\title{
Promoting R\&D intentions in primary care organization through strategic communication
}

\author{
Helena Morténius ${ }^{1,2 *}$ \\ ${ }^{1}$ Department of Primary Health Care, The Sahlgrenska Academy, University of Gothenburg, Sweden \\ ${ }^{2}$ Department of Health Care, Halland Region, Halmstad, Sweden
}

\section{Background}

We present a short paper based on a doctoral dissertation [1] and supplementary articles. Despite the long and successful patient care history of primary care in Sweden, a research-oriented attitude has been more or less limited in this context [2,3]. At the same time the patient's access to information has been simplified which in turn has contributed to an essential influence on the patients' demand for upto-date healthcare. This situation has increased the demand for staff's updated professional scientific knowledge and willingness to change significantly. One way to promote this situation goes through a research and development interest (R\&D) in the context, by means of strategic communication, which is a relatively new interdisciplinary field.

\section{Aims}

Intervention: The aim of the intervention's cohort was to promote the primary care staff's knowledge and attitudes to research interest as well as their willingness for change in the context.

Evaluation: The aim of the study was to evaluate the role of the strategic communication in the creation of these intentions over time.

\section{Methods}

The intervention process: A staff cohort comprising all employees $(\mathrm{N}=1,276)$ was initiated. The intervention was based on strategic communication. The basis of strategic communication is a theoretical platform originating in communication science as well as sociology, psychology and political science. The concept of communication is described as a joint activity between the actors involved, who are no longer called sender and receiver but participants, and contact is circular or spiral shaped [4]. One solution to the problem of low selfefficacy and an organisational culture that is not ready to change may be the application of diffusion theories such as Diffusion of innovations [5] and Social learning theory [6].

Oral, written and digital communication channels were used. The study design was longitudinal to allow follow-up and evaluation of the influence of strategic communication over time on staff members' intention to engage in $\mathrm{R} \& \mathrm{D}$, measured 7 and 12 years after the start of the strategic communication.

The intervention context: A primary care organisation in southwest Sweden.

Data collection and analysis: A questionnaire comprising fixed response alternatives in combination with an open-ended question. The questions were validated by a factor analysis $[7,8]$, and the degree of reliability was measured with Cronbach's alpha coefficient [9].
Multivariate tests were employed to analyse the answers to the fixed response alternatives and qualitative content analysis was applied to the open-ended question. An ethnographic study comprising observations, interviews and analysis of documents was conducted to elucidate the significance of the organisational culture in the studied context.

Results: Strategic communication contributed to almost all primary care staff gaining knowledge of $\mathrm{R} \& \mathrm{D}$, more than half of whom became interested in the subject $[10,11]$. The intervention also resulted in more than half of the primary care staff members developing new thoughts and ideas and a third of them had changed or intended to change their work practices (7 year follow-up). This positive attitude increased over time and every second staff member exhibited an intention to engage in $\mathrm{R} \& \mathrm{D}$ at the 12 year follow-up [12]. These positive attitudes included the most occupational categories such as physicians, nurses [13] and dentists [14] etc. All results were statistically significant. The organisational culture emerged as an important factor, influencing the values and attitudes in relation to the intention to engage in $\mathrm{R} \& \mathrm{D}$ [15].

\section{Realization and conclusions}

The vision of the implementation was realised in four steps, which together lead to the promotional platform for future implementation of research findings and EBP within primary care. The four steps follow a sequential principle:

1. A culture prepared for change, contributes to strengthening an organisation's readiness to change and prepares the organisational culture for the implementation process.

2. Strategic approach, the theory-driven strategic communication consisting of established communication channels and the interchannel synergy effect includes all staff members and contributes to a holistic cultural view of R\&D.

3. Evidence, the result was obtained from a long-term follow-up based on an intervention cohort that included $70 \%$ of all primary care staff in the region.

${ }^{*}$ Correspondence to: Helena Morténius, MD, PhD, Department of Primary Health Care, The Sahlgrenska Academy, University of Gothenburg, Gothenburg, Sweden, E-mail: helena.mortenius@regionhalland.se

Key words: change in work practice, interest in $R \in D D$, primary healthcare, research and development, strategic communication, validated instrument.

Received: February 02, 2020; Accepted: February 15, 2020; Published: February 17,2020 
4. Change, the change in attitude was a gradual process that took place over time (12 years).

The systematic execution of these steps means that all the findings can be considered new knowledge. To our knowledge, no previous study design included a long-term perspective of a primary care culture prepared for change by means of strategic communication influenced by a theoretical platform prior to the implementation of R\&D.

\section{Current staff's cohort}

This staff's cohort, including its facilitators, is currently in the context of primary healthcare. Facilitators' action is an exciting step in upcoming promotional activities within the cohort. Management's ambition and existing allocated resources determine the continuation of this staff cohort in the organization.

\section{References}

1. Mortenius H (2012) Implementation of research and development in primary care by means of strategic communication. Sweden: Department of Public Health and Community Medicine, Institute of Medicine, Sahlgrenska Academy at University of Gothenburg.

2. Funk SG, Champagne MT, Wiese RA, Tornquist EM (1991) BARRIERS: the barriers to research utilization scale. Appl Nurs Res 4: 39-45. [Crossref]

3. Whitford DL, Walker C, Jelley D, Clarke CL (2005) Developing R\&D capacity in a primary care trust: Use of the R\&D culture index. Prim Health Care Res Dev 6: $110-116$.

4. Fiske J (1990) Introduction to communication studies. ( $2^{\text {nd }}$ edn). Studies in culture and communication. 1990, London; New York: Routledge.
5. Rogers EM. Diffusion of innovations. ( $5^{\text {th }}$ edn). 2003, New York: Free Press.

6. Bandura A (1977) Social learning theory. Englewood Cliffs NJ. Prentice Hall.

7. Gorsuch RL (1983) Factor Analysis. Hillsdale, NJ: Erlbaum.

8. Hogarty K, Hines C, Kromrey J, Ferron J, Mumford K (2005) The Quality of Factor Solutions in Exploratory Factor Analysis: The Influence of Sample Size, Communality, and Overdetermination. Educational and Psychological Measurement 65: 202-226.

9. Rattray J, Jones MC (2007) Essential Elements of Questionnaire Design and Development. J Clin Nurs 16: 234-243. [Crossref]

10. Mortenius H, Marklund B, Palm L, Fridlund B, Baigi A (2012) The utilization of knowledge of and interest in research and development among primary care staff by means of strategic communication - a staff cohort study. J Eval Clin Pract 18: 768-775. [Crossref]

11. Mortenius H, Marklund B, Palm L, Bjorkelund C, Baigi A (2012) Implementation of innovative attitudes and behaviour in primary health care by means of strategic communication: a 7-year follow-up. J Eval Clin Pract 18: 659-665. [Crossref]

12. Morténius H, Baigi A (2019) Promoting the creation of R\&D intentions in primary healthcare measured by a validated instrument. Health Res Policy Syst 17: 107.

13. Mortenius H, Hildingh C, Fridlund B (2016) Strategic communication intervention to stimulate interest in research and evidence-based practice: a 12-year follow-up study with registered nurses. Worldviews Evid Based Nurs 13: 42-49. [Crossref]

14. Morténius H, Twetman S (2017) Creating research and development awareness among dental care professionals by use of strategic communication: a 12 -year intervention study. BMC Oral Health 17: 164. [Crossref]

15. Mortenius H, Baigi A, Palm L, Fridlund B, Bjorkelund C, et al. (2015) Impact of the organisational culture on primary care staff members' intention to engage in research and development. J Health Organ Manag 29: 234-251. [Crossref]

Copyright: @2020 Morténius H. This is an open-access article distributed under the terms of the Creative Commons Attribution License, which permits unrestricted use, distribution, and reproduction in any medium, provided the original author and source are credited. 